\title{
Persepsi Guru tentang Inventarisasi Sarana Pendidikan di Sekolah Menengah Kejuruan Negeri 1 Tarusan
}

\author{
Yudita Friseilli ${ }^{1}$, Hanif Al Kadri ${ }^{2}$, Sufyarma Marsidin ${ }^{3}$, Hadiyanto ${ }^{4}$ \\ 1,2,3,4 Administrasi Pendidikan, Universitas Negeri Padang \\ Penulis $^{1}$, e-mail: yuditafriseilli@gmail.com \\ Penulis ${ }^{2}$, e-mail: hanifalkadri@fip.unp.ac.id \\ Penulis ${ }^{3}$, e-mail: sufyarma1954@gmail.com \\ Penulis ${ }^{4}$, e-mail: hadiyanto@fio.unp.ac.id
}

\begin{abstract}
This study aims to determine teachers' perceptions of the inventory of educational facilities at Tarusan 1 State Vocational High School, the authors conclude that what is used as an indicator of an inventory of educational facilities is recording, responsibility and cooperation. This study is a one-variable study, namely the Teacher's Perception of the Inventory of Educational Facilities at SMK Negeri 1 Tarusan. This type of research is population research, the population in this study is 62 teachers using total sampling technique or the entire population is sampled. The location of this research is in the coastal district of Selata in XI Tarusan sub-district to be precise at SMK Negeri 1 Tarusan, the research which is intended to investigate the conditions, conditions, or others that have been mentioned, the results of which are presented in the form of research reports, data analysis techniques are carried out in accordance with the purpose and type of research carried out, the data analysis was carried out by calculating based on the answers given by the respondents by managing the collected questionnaires. The type of data that the writer uses in this study is primary data, and the source of the data needed in this study is the source of data obtained from the teacher. The research instrument used a questionnaire with a Likert scale model that had been tested to see the validity of the questionnaire and analyzed using the Spearman Rank Correlation (rho) formula and the reliability of the questionnaire. Then the results of the research concluded that the recording indicators obtained an average score of $3.79 \%, 3.78 \%$ responsibility and $3.80 \%$ cooperation that the teacher's perception of the inventory of educational facilities at the Tarusan 1 Vocational High School is in a good category.
\end{abstract}

\begin{abstract}
Abstrak
Penelitian ini bertujuan untuk mengetahui bagaimana persepsi guru tentang inventarisasi sarana pendidikan di Sekolah Menengah Kejuruan Negeri 1 Tarusan, penulis mengambil kesimpulan bahwa yang dijadikan indikator inventarisasi sarana pendidikan adalah pencatatan, tanggung jawab dan kerjasama. Penelitian ini merupakan penelitian satu variabel yaitu tentang Persepsi Guru Tentang Inventarisasi Sarana Pendidikan di SMK Negeri 1 Tarusan. Jenis penelitian ini yaitu penelitian populasi, populasi pada penelitian ini 62 orang guru dengan menggunakan teknik total sampling atau seluruh populasi dijadikan sampel. Lokasi penelitian ini berada di kabupaten pesisir selatan di kecamatan XI Tarusan tepatnya di SMK negeri 1 Tarusan ,penelitian yang dimaksudkan untuk menyelidiki keadaan, kondisi, atau lain-lain yang sudah disebutkan, yang hasilnya dipaparkan dalam bentuk laporan penelitian, teknik analisis data dilakukan sesuai dengan tujuan dan jenis penelitian yang dilaksanakan maka analisis data dilakukan dengan perhitungan yang didasarkan pada jawaban yang diberikan responden dengan mengelola angket yang sudah terkumpul. Jenis data yang penulis gunakan dalam penelitian ini adalah data primer, dan sumber data yang dibutuhkan dalam penelitian ini adalah sumber data yang diperoleh dari guru. Instrumen penelitian ini menggunakan angket dengan model skala likert yang telah di uji coba kan untuk melihat validitas angket dilakukan analisis menggunakan rumus Korelasi Spearman Rank (rho) dan reliabilitas angket. Maka didapatkan hasil penelitian yang disimpulkan untuk indikator pencatatan memperoleh skor rata-rata 3,79\%, tanggung jawab 3.78\% dan kerjasama 3.80\% bahwasanya persepsi guru tentang inventarisasi sarana pendidikan di Sekolah Menengah Kejuruan Negeri 1 Tarusan berada dalam kategori yang baik.
\end{abstract}

Kata Kunci: Persepsi; Guru; Inventarisasi; Sarana Pendidikan 
How to Cite: Friseilli Yudita dan Hanif Al Kadri. 2021. Persepsi Guru tentang Inventarisasi Sarana Pendidikan di Sekolah Menengah Kejuruan Negeri 1 Tarusan. Journal of Educational Administration and Leadership, Vol (N): pp. XX-XX, DOI: doi.org/10.24036/jeal.v2i1

This is an open access article distributed under the Creative Commons 4.0 Attribution License, which permits unrestricted use, distribution, and reproduction in any medium, provided the original work is properly cited. $\odot 2020$ by author.

\section{Pendahuluan}

Di era globalisasi ini membutuhkan kesiapan yang lebih matang dalam segala hal terutama di bidang pendidikan yang menjadi salah satu andalan dalam mempersiapkan sumber daya manusia yang dibutuhkan untuk menghadapi tantangan zaman. Di dalam daftar inventaris terdapat catatan kondisi dan jumlah barang yang dimiliki, karena dalam penggunaannya bukan tidak mungkin volumenya berkurang, rusak, hilang dan lain-lain. Pencatatan tersebut akan memudahkan terlaksananya kegiatan pengendalian atau penguasaan barang, baik jumlah maupun jenisnya serta kondisi atau mutunya.

Adapun kenyataan yang penulis temukan di lapangan yaitu masih terlihat adanya sarana yang belum diberikan pengkodean atau penomoran, kurangnya informasi data mengenai kondisi barang yang sudah rusak atau masih bagus, perhatian yang dilakukan oleh pihak sekolah terhadap ketersediaan sarana pendidikan di sekolah yang masih sangat minim sekali, hal ini terlihat ketika masih ada siswa yang mencari kursi atau meja ke kelas-kelas lainnya karena tidak sesuainya jumlah kursi dan meja dengan jumlah siswa yang akan belajar di ruang kelas tersebut.

Landasan teori dalam penelitian menggunakan referensi dari beberapa penelitian terdahulu, diantaranya penelitian Nur Anita pada tahun 2011 Penelitian ini memberikan alternatif metode inventaris melalui suatu perancangan aplikasi inventaris barang yang mengacu pada pengolahan data elektronik. Persamaan penelitian dengan penelitian yang akan peneliti lakukan adalah mengkaji tentang Inventaris Sarana Pendidikan. Perbedaannya terhadap penelitian di atas dengan penelitian yang akan peneliti lakukan terletak pada lokasi, metode penelitian dan bidang kajiannya. Menurut (Syahril, 2018) inventarisasi adalah proses pencatatan dan penyusunan daftar barang inventaris (dalam hal ini adalah barang yang kepemilikannya dikuasai oleh negara ) secara tertib berdasarkan ketentuan, tata cara dan aturan-aturan yang berlaku. . Menurut Arikunto dan Yuliana (2008) sarana pendidikan yaitu segala fasilitas yang dibutuhkan dalam proses belajar mengajar baik yang bergerak, sehingga pencapaian tujuan pendidikan dapat berjalan dengan lancar, efektif, teratur, dan efisien. Menurut Jejen (2015) menyatakan bahwa sarana adalah media atau alat pembelajaran agar pendidikan dapat berjalan dengan efektif. Inventarisasi sesuatu kegiatan menjalankan pengurusan, penyelenggaraan, pengaturan serta pencatatan atau pendaftaran benda-benda milik Negara kedalam suatu buku inventaris yang sudah disediakan yang dicatat dengan tertib serta teratur berdasarkan prosedur yang berlaku, baik benda yang bergerak atau tidak bergerak, yang seluruhnya jadi hak sekolah yang wajib di inventariskan supaya dapat mempermudah informasi mengenai benda-benda yang terdapat di sekolah itu alhasil terselenggaranya tujuan pembelajaran yang efektif serta efisien.

Tujuan akan pelaksanaan penelitian ini yakni untuk mengetahui bagaimana persepsi guru terhadap inventarisasi sarana pendidikan yang telah berlaku di SMK Negeri 1 Tarusan. Dengan menyertakan pertanyaan penelitian yang hendak dijawab dengan penelitian ini yakni, beberapa baik pencatatan dalam pelaksanaan inventarisasi di SMK Negeri 1 Tarusan, seberapa baik tanggung jawab dalam pelaksanaan inventarisasi di SMK Negeri 1 Tarusan, seberapa baik kerja sama dalam pelaksanaan inventarisasi di SMK Negeri 1 Tarusan.

\section{Metode Penelitian}

Jenis penelitian ini memakai metode Deskriptif, Penelitian deskriptif dimaksudkan guna menggambarkan suatu hal yang sedang terjadi ketika penelitian. Penelitian deskriptif yakni penelitian yang bertujuan guna mengumpulkan informasi tentang status gejala yang ada, yaitu keadaan gejala berdasarkan apa adanya ketika penelitian dijalankan. Lokasi yang peneliti ambil dalam penelitian ini berasal dari Kota Padang lebih tepatnya di Kabupaten Pesisir Selatan, Kecamatan XI Tarusan, di SMK Negeri 1 Tarusan

Penelitian ini memakai populasi sebanyak 62 orang guru di Sekolah Menengah Kejuruan Negeri 1 Tarusan dengan memakai teknik total sampling atau semua populasi digunakan sampel. Penelitian ini memakai instrumen berupa angket/kuesioner yang berguna dalam penentuan validitas dan reliabilitas yaitu model skala likert. Pada penelitian ini peneliti mengadakan analisis data menggunakan beberapa langkah, yaitu melakukan verifikasi data, pengelompokan item berdasarkan indikator, kemudian memberikan skor ke masing-masing jawaban dari responden, selanjutnya data diolah dengan memakai rumus mean (skor rata-rata), serta terakhir yang dilakukan adalah menentukan kualitas atau gambaran hasil penelitian tentang inventarisasi sarana dengan menggunakan kriteria batas nyata skala likert dan kemudian sehingga akan mengetahui bagaimana persepsi guru tentang inventarisasi sarana pendidikan di Sekolah Menengah Kejuruan Negeri 1 Tarusan dengan tingkat pencapaian skor sangat baik, baik, cukup baik, kurang baik, tidak baik. Maka didapatkan hasil penelitian yang 
disimpulkan untuk indikator pencatatan memperoleh skor rata-rata 3,79\%, tanggung jawab 3.78\% dan kerjasama $3.80 \%$ bahwasanya persepsi guru tentang inventarisasi sarana pendidikan di Sekolah Menengah Kejuruan Negeri 1 Tarusan berada dalam kategori yang baik.

\section{Hasil dan Pembahasan}

\subsection{Hasil}

Berdasarkan Hasil penelitian serta pembahasan yang terkait dengan inventarisasi sarana pendidikan di Sekolah Menengah Kejuruan Negeri 1 Tarusan dapat dilihat dari tiga indikator, yang pertama pencatatan yang berada pada kategori baik dengan tingkat pencapaian skor 3,97\%, yang kedua tanggung jawab yang ada pada kategori baik dengan tingkat pencapaian skor 3,78\%, yang ketiga kerja sama yang berada pada kategori baik dengan tingkat pencapaian skor 3.80\%. Hal ini dapat diartikan bahwa inventarisasi sarana di SMK Negeri 1 Tarusan sudah terlaksana dengan baik namun harus lebih ditingkatkan lagi.

\subsection{Pembahasan}

persepsi guru tentang inventarisasi sarana di SMK Negeri 1 Tarusan dalam pencatatan, didasarkan pada hasil olah data penelitian yang dilakukan penulis skor tertinggi terdapat pada item yang menyatakan semua sarana yang ada di sekolah dicatat dalam buku/ data inventaris dengan skor 3,97. Sedangkan skor terendah terdapat pada item yang menyatakan pegawai melihat kembali barang yang sudah di catat dalam buku inventaris demi menjaga ketertiban administrasi barang dengan skor 3,58. Hal ini berarti petugas melakukan pekerjaannya dengan baik berdasarkan aturan yang telah ditetapkan, seperti yang dijelaskan oleh (Syahril, 2004), buku yang digunakan untuk mencatat semua data barang inventaris dapat berfungsi sebagai sumber informasi mengenai segala data yang diperlukan tentang barang inventaris yang dimiliki suatu lembaga/sekolah.

Sedangkan skor rata-rata terendah terdapat pada item yang menyatakan melihat kembali barang yang sudah dicatat dalam buku inventaris demi ketertiban administrasi barang dengan skor 3,58. Hal ini sama dengan pegawai tidak melihat kembali sarana yang sudah di catat guna untuk memastikan kembali barang-barang tersebut, hal yang membuatnya rendah karena pegawai tidak melihat kembali karena pencatatan sarana di awal pegawai sudah merasa sarana dalam keadaan lengkap.

Usaha yang bisa ditempuh guna mengantisipasi hal tersebut yakni memberikan saran kepada pegawai sarana untuk melihat kembali barang yang sudah di catat dalam buku inventaris guna mempermudah pelaksanaan kegiatan kontrol atau pengawasan barang nanti nya, baik yang berkaitan dengan kuantitas serta jenis nya maupun kondisinya serta kualitasnya. Karena dalam pemakaian nya pasti ada yang berkurang, rusak dan hilang. Untuk itu pegawai harus melihat kembali barang tersebut/sarana minimal 1 kali 3 bulan. Inventarisasi dimaksudkan guna memberi tanda pengenal untuk seluruh fasilitas di industri/sekolah. Inventaris yang dibuat mesti memiliki informasi yang jelas serta gampang dipahami secara cepat, alhasil bisa menunjang kelancaran pekerjaan.

Persepsi guru tentang inventarisasi sarana di SMK Negeri 1 Tarusan terhadap tanggung jawab inventarisasi sarana dapat dilihat bahwa item tertinggi terdapat pada item yang menyatakan sebagaimana pegawai dengan penuh tanggung jawab dalam menyelesaikan tugas dengan skor 3,92. Hal ini terlihat ketika pegawai menyelesaikan pekerjaan tepat waktu juga tidak menunda-nunda pekerjaan yang diberikan oleh atasan seperti misalnya membuat daftar laporan triwulan untuk dilaporkan kepada Kepala Dinas Pendidikan Kabupaten/kota setempat. Pegawai disebut sempurna jika memiliki tanggung jawab yang dilaksanakan secara baik. Tanggung jawab yang dibebankan atasan untuk bawahan musti terdapat umpan balik, kepala sekolah wajib dapat memberikan arahan serta bimbingan berkenaan hasil kerja pegawai yang sudah dikerjakan. Hal tersebut ditempuh supaya pegawai bisa mengetahui jika terdapat kesalahan, supaya kesalahan itu tidak terjadi lagi dalam mengerjakan tugas - tugas selanjutnya.

Sedangkan item terendah terdapat pada item yang menyatakan atas kesalahan yang dilakukan dalam lembaga pegawai siap menerima konsekuensinya dengan skor 3,66. Pada dasarnya Kesalahan yang dilakukan lembaga sama hal nya dengan kesalahan pegawainya sebab tanggung jawab adalah sikap atau kesanggupan individu untuk mengerjakan pekerjaan berdasarkan rencana yang sudah ditentukan serta sikap mengambil resiko terhadap pekerjaan yang dilaksanakan. Upaya yang dilakukan pimpinan dengan melakukan pendekatan kepada pegawai, melihat bagaimana pekerjaan yang dikerjakan nya agar menghindari kesalahan yang mengakibatkan nilai lembaga jadi menurun.

Berdasarkan uraian diatas dapat disimpulkan bahwa tanggung jawab tidak hanya untuk diri sendiri namun juga tanggung jawab atas lembaga dimana tempat kita bekerja. pegawai/ kepala sekolah harus mengajak pegawai lainnya untuk selalu mengikuti dan mentaati peraturan lembaga yang telah ditetapkan. bertambah tinggi tingkat partisipasi, bertambah besar rasa memiliki, bertambah besar juga rasa tanggung jawab serta bertambah besar rasa tanggung jawab, bertambah besar juga tingkat dedikasi untuk lembaga.

Persepsi guru tentang inventarisasi sarana di SMK Negeri 1 Tarusan berdasarkan kerja sama terhadap inventarisasi sarana pendidikan pada item yang menyatakan melakukan musyawarah apabila terjadi perbedaan pendapat dalam menyelesaikan pekerjaan dengan mendapatkan skor rata-rata tertinggi yaitu 4.02. hal ini 
membuktikan bahwa kerja sama tim dalam bekerja tinggi karena Kerjasama tim jadi suatu kebutuhan untuk membuahkan keberhasilan kerja. Kerjasama tim akan jadi sebuah daya dorong yang mempunyai energi. Setap pegawai juga harus mempertahankan prinsip ringan sama dijinjing berat sama dipikul, karena bermusyawarah akan membuahkan ide-ide yang gemilang untuk mengatasi masalah yang ada.

Sedangkan skor terendah terdapat pada item yang menyebutkan bahwa pegawai berpartisipasi aktif dalam memberikan kritik, saran serta masukan yang membangun guna tim kerja dengan mendapatkan skor rata-rata terendah yaitu 3,77. Rendahnya partisipasi pegawai dalam memberikan kritik, saran dan masukan dan keterlibatan pegawai dalam pengambilan keputusan mungkin disebabkan karena beberapa faktor diantaranya pegawai kurang peduli dengan lembaga sehingga pegawai cenderung bekerja secara rutinitas saja, serta pegawai tidak dilibatkan dalam pengambilan keputusan. Upaya yang harus dilakukan mengajak pegawai untuk berperan dan berpartisipasi pada aktivitas-aktivitas yang dilakukan oleh lembaga serta dalam pengambilan keputusan. Walaupun tidak semua pengambilan keputusan mengikutsertakan pegawai tetapi keputusan yang menyangkut dengan pekerjaan hendaknya pimpinan melibatkan pegawai.

Kerja sama penting dilaksanakan dalam organisasi, agar pekerjaan yang berat serta masalah - masalah yang sulit dapat diatasi dengan bersama - sama, sebab dari bekerja sama bisa meraih tujuan organisasi dengan hasil maksimal. Menurut Sastrohadiwiryo, (2003) kerja sama yakni kemampuan dari tenaga kerja guna bekerja bersama- sama terhadap orang lain untuk mengerjakan suatu tugas serta pekerjaan yang sudah ditentukan alhasil mendapat daya guna dan hasil guna yang sebesar - besarnya. Sementara menurut penjelasan (Pandji, 2006) menjelaskan kerjasama adalah kesediaan para karyawan guna bekerja dengan bersama-sama terhadap rekan sekerjanya ataupun bersama atasan mereka guna meraih tujuan bersama dan kesetiaan guna saling mendukung antara rekan sekerja berkenaan terhadap tugasnya.. Harapannya kedepan untuk kerja sama baik dalam tim maupun dalam memberikan kritik dan saran lebih ditingkatkan lagi. Karena kemajuan suatu lembaga dilihat sebagaimana anggotanya menjalankan dan membawa lembaga bersama-sama ke arah yang lebih baik lagi. Serta membangun dan memelihara sikap saling percaya. Menurut Gistituati (2012) mengatakan bahwasanya hubungan yang saling mempercayai dibangun berdasarkan pada rasa saling ketergantungan. Kebutuhan akan kepercayaan muncul di organisasi karena adanya tingkat ketergantungan yang tinggi. Kepercayaan adalah meyakini kebenaran suatu hal, sehingga kita mau dan ingin menghargainya.

Secara keseluruhan pengelolaan data mengenai Persepsi Guru Tentang Inventarisasi Sarana Pendidikan di SMK Negeri 1 Tarusan dijabarkan di bawah ini dalam bentuk tabel, sebagai berikut

\section{Rekapitulasi skor rata-rata Persepsi Guru Tentang Inventarisasi Sarana Pendidikan di SMK Negeri 1} Tarusan

\begin{tabular}{|l|l|l|l|}
\hline No & Indikator & Skor rata-rata & keterangan \\
\hline 1 & Pencatatan & 3.79 & Baik \\
\hline 2 & Tanggung jawab & 3.78 & Baik \\
\hline 3 & Kerja sama & 3.8 & Baik \\
\hline \multicolumn{2}{|l|}{ Rata-rata } & $\mathbf{3 . 7 9}$ & Baik \\
\hline
\end{tabular}

Berdasarkan rekapitulasi rata-rata masing-masing sub indikator pada Persepsi Guru tentang Inventarisasi Sarana Pendidikan di SMK Negeri 1 Tarusan yang bisa diketahui dari tabel tersebut jika skor rata-rata tertinggi pada indikator kerja sama dengan skor 3.8 sedangkan skor pada indikator Tanggung jawab dengan skor 3,78 dan pada indikator kerjasama dengan skor 3.80. Secara keseluruhan skor rata-rata dari Persepsi Guru Tentang Inventarisasi Sarana Pendidikan di SMK Negeri 1 Tarusan yakni 3,79. Skor tersebut ada dalam kategori baik, hal tersebut artinya jika Persepsi Guru Tentang Inventarisasi Sarana Pendidikan di SMK Negeri 1 Tarusan terlaksana dengan baik. Oleh karena itu inventaris sarana pendidikan harus mempertahankan dan juga berusaha meningkatkan pelaksanaan inventaris sarana pendidikan agar terlihat lebih baik lagi.

\section{Simpulan}

Berlandaskan hasil penelitian yang sudah dijabarkan sebelumnya, mengenai persepsi Guru Tentang Inventarisasi Sarana Pendidikan Di Sekolah Menengah Kejuruan Negeri 1 Tarusan dapat ditarik kesimpulan sebagai berikut, dimana Inventaris Sarana Pendidikan di SMK Negeri 1 Tarusan yang dilihat dari indikator pencatatan berdasarkan berada pada pada kategori baik yaitu 3,79\%. Hal ini berarti pencatatan inventarisasi sarana pendidikan di SMK Negeri 1 Tarusan telah terlaksana dengan baik, namun perlu adanya peningkatan agar lebih baik dan tergolong pada kategori sangat baik Inventaris sarana pendidikan di SMK Negeri 1 Tarusan yang dilihat dari indikator tanggung jawab berlandaskan skor rata-rata yaitu 3,78. Skor tersebut ada dalam kategori Baik. Hal ini berarti Tanggung jawab inventarisasi sarana pendidikan di SMK Negeri 1 Tarusan telah terlaksana dengan baik, namun perlu adanya peningkatan agar lebih baik dan tergolong pada kategori sangat 
baik Inventaris sarana pendidikan di SMK Negeri 1 Tarusan yang dilihat dari indikator kerjasama berlandaskan skor rata-rata yaitu 3.8. Skor ini berada ada dalam kategori Baik. Hal ini berarti kerja sama inventarisasi sarana pendidikan di SMK Negeri 1 Tarusan telah terlaksana dengan baik, namun perlu adanya peningkatan agar lebih baik dan tergolong pada kategori sangat baik.

Berdasarkan kesimpulan tersebut bisa diberikan sejumlah saran-saran yakni, untuk pencatatan diharapkan kepala sekolah memberikan masukan kepada pegawai untuk mengecek kembali sarana yang sudah dicatat di dalam buku pencatatan sarana, untuk tanggung jawab kepala sekolah harus mengajak pegawai lainnya untuk selalu mengikuti dan mentaati peraturan lembaga yang telah ditetapkan. Bertambah tinggi tingkat partisipasi, bertambah besar rasa memiliki, makin besar juga rasa tanggung jawab serta bertambah besar rasa tanggung jawab, bertambah besar juga tingkat dedikasi bagi lembaga. Untuk kerjasama setiap pegawai harus meningkatkan rasa kebersamaan, meningkatkan kepedulian terhadap keberhasilan lembaga. Untuk kerjasama setiap pegawai harus meningkatkan rasa kebersamaan, meningkatkan kepedulian terhadap keberhasilan lembaga, karena salah satu faktor yang mempengaruhi kinerja guru menurut (Alkadri et al., 2020) adalah iklim sekolah dalam suatu lembaga atau organisasi. Iklim sekolah atau suasana lingkungan kerja di sekolah adalah segala sesuatu yang dialami oleh guru dan warga sekolah ketika berinteraksi di dalam lingkungan sekolah. Iklim sekolah yang kondusif mempengaruhi kinerja anggota organisasi sekolah. Dengan kata lain, maju atau mundurnya sekolah bergantung pada kemampuan sekolah tersebut menciptakan lingkungan dan kesediaan lingkungan untuk menerima keberadaanya

\section{Daftar Rujukan}

Alkadri, H., Ideswal, I., \& Yahya, Y. (2020). Kontribusi Iklim Sekolah dan Kepemimpinan Kepala Sekolah terhadap Kinerja Guru Sekolah Dasar. Jurnal Basicedu, 4(2), 460-466.

\section{Gistituati, Nurhizrah. (2012). Manajemen Sekolah: Konsep Dasar Manajemen Sekolah dan} Manajemen Program Akademik. Padang: UNP PRESS

Jejen Musfah, Manajemen Pendidikan, ( Jakarta: Prenada Priama Group, 2015)

Pandji. (2006). Psikologi Kerja. Rineka Cipta.

Sastrohadiwiryo. (2003). Manajemen Tenaga Kerja Indonesia. Bumi Aksara.

Syahril. (2004). Bahan Ajar Manajemen Sarana Prasarana Pendidikan.

Suharsimi Arikunto dan Lia Yuliana, S.Pd. 2008, Manajemen Pendidikan(Yogyakarta: Aditya Media)

Syahril. (2018). Manajemen sarana dan prasarana pendidikan. Padang Sukabina Press. 